\title{
Impact of wind-driven rain on historic brick wall buildings in a moderately cold and humid climate: Numerical analyses of mould growth risk, indoor climate and energy consumption
}

Masaru, Abuku; Janssen, Hans; Roels, Staf

Published in:

Energy and Buildings

Link to article, DOI:

10.1016/j.enbuild.2008.07.011

Publication date:

2009

Link back to DTU Orbit

Citation (APA):

Masaru, A., Janssen, H., \& Roels, S. (2009). Impact of wind-driven rain on historic brick wall buildings in a moderately cold and humid climate: Numerical analyses of mould growth risk, indoor climate and energy consumption. Energy and Buildings, 41(1), 101-110. https://doi.org/10.1016/j.enbuild.2008.07.011

\section{General rights}

Copyright and moral rights for the publications made accessible in the public portal are retained by the authors and/or other copyright owners and it is a condition of accessing publications that users recognise and abide by the legal requirements associated with these rights.

- Users may download and print one copy of any publication from the public portal for the purpose of private study or research.

- You may not further distribute the material or use it for any profit-making activity or commercial gain

- You may freely distribute the URL identifying the publication in the public portal 
Postprint: Abuku M, Janssen H, Roels S, 2009. Impact of wind-driven rain on historic brick wall buildings in a moderately cold and humid climate: numerical analyses of mould growth risk, indoor climate and energy consumption, Energy and Buildings, 41: 101-110. doi:10.1016/j.enbuild.2008.07.011

\title{
Impact of wind-driven rain on historic brick wall buildings in a moderately cold and humid climate: numerical analyses of mould growth risk, indoor climate and energy consumption
}

\author{
Masaru Abuku ${ }^{\text {a, }}$, Hans Janssen ${ }^{\text {b }}$, Staf Roels ${ }^{a}$ \\ a Laboratory of Building Physics, Department of Civil Engineering, Katholieke Universiteit Leuven, \\ Kasteelpark Arenberg 40, 3001 Leuven, Belgium \\ ${ }^{\mathrm{b}}$ Department of Civil Engineering, Technical University of Denmark, Brovej - Building 118, $2800 \mathrm{Kgs}$. \\ Lyngby, Denmark \\ * Corresponding author: Masaru Abuku, Tel: +32 16 321348, Fax: +32 16321980 , \\ E-mail:masaru.abuku@bwk.kuleuven.be
}

\begin{abstract}
This paper gives an onset to whole building hygrothermal modelling in which the interaction between interior and exterior climates via building enclosures is simulated under a moderately cold and humid climate. The focus is particularly on the impact of wind-driven rain (WDR) on the hygrothermal response, mould growth at interior wall surfaces, indoor climate and energy consumption. First the WDR load on the facades of a $4 \times 4 \times 10 \mathrm{~m}^{3}$ tower is determined. Then the hygrothermal behaviour of the brick walls is analysed on a horizontal slice through the tower. The simulations demonstrate that the impact of WDR loads on the moisture contents in the walls is much larger near the edges of the walls than at the centre. The obtained relative humidity and temperature at the interior wall surfaces are combined with isopleths of generalised spore germination time of fungus mould. The results show that WDR loads can have a significant impact on mould growth especially at the edges of the walls. Finally, for the case analysed, the WDR load causes a significant increase of indoor relative humidity and energy consumption for heating.
\end{abstract}

Keywords: wind-driven rain, driving rain, durability, mould growth, indoor climate, energy consumption, historical buildings, cold climate, moisture transfer, numerical simulation 


\section{Nomenclature}

$\begin{array}{ll}d & \text { thickness of the wall }(\mathrm{m}) \\ c & \text { specific heat }(\mathrm{J} / \mathrm{kgK}) \\ g & \text { flux }\left(\mathrm{W} / \mathrm{m}^{2} \text { or } \mathrm{kg} / \mathrm{m}^{2} \mathrm{~s}\right) \\ I_{h} & \text { horizontal rainfall intensity }(\mathrm{mm} / \mathrm{h}) \\ I_{W D R} & \text { wind-driven rain intensity on a building facade }(\mathrm{mm} / \mathrm{h}) \\ k_{h} & \text { heat conductivity }(\mathrm{W} / \mathrm{mK} \text { or } \mathrm{W} / \mathrm{mPa}) \\ k_{m} & \text { moisture permeability }(\mathrm{s} \text { or } \mathrm{kg} / \mathrm{msK}) \\ L_{v} & \text { heat of vaporisation }(\mathrm{J} / \mathrm{kg}) \\ p & \text { vapour pressure }(\mathrm{Pa}) \\ p_{c} & \text { capillary pressure }(\mathrm{Pa}) \\ S & \text { radiative heat exchange }\left(\mathrm{W} / \mathrm{m}^{2}\right) \\ T & \text { temperature }(\mathrm{K}) \\ U & \text { wind speed }(\mathrm{m} / \mathrm{s}) \\ x, x^{\prime}, y^{\prime}, z^{\prime} & \text { coordinates }(\mathrm{m}) \\ x_{i} & \text { distance from the corner }(\mathrm{m})\end{array}$

Greek letters

$\begin{array}{ll}\alpha & \text { surface film coefficient for heat transfer }\left(\mathrm{W} / \mathrm{m}^{2} \mathrm{~K}\right) \\ \beta & \text { surface film coefficient for moisture transfer }(\mathrm{s} / \mathrm{m}) \\ \eta & \text { global catch ratio }(-) \\ \theta & \text { wind direction }\left({ }^{\circ}\right)\end{array}$

Subscripts

$\begin{array}{ll}c / t & \text { convective/total } \\ e / i & \text { external/internal } \\ h / m & \text { heat/moisture } \\ l / v & \text { liquid/vapour } \\ r e f & \text { reference } \\ s & \text { surface } \\ W D R & \text { wind-driven rain }\end{array}$

Acronyms

BES building energy simulation

CFD computational fluid dynamics

$\mathrm{RH} \quad$ relative humidity

WDR wind-driven rain 


\section{Introduction}

Building Energy Simulation (BES) models have been under development since the 1970s, for the numerical prediction of the thermal condition and energy performance of a building. Though most BES models nowadays also (partially) solve the hygric balance, moisture analysis is mainly limited to water vapour transport and its influence through latent heat effects and interior moisture buffering. The comprehensive hygrothermal interaction between the exterior and interior climates, as dealt with in building envelope models [e.g. 1-4], is only incorporated to a limited extent. Recently, Nakhi [5], Holm et al. [6], Rode et al. [7] and Mendes et al. [8] have given an onset to whole building hygrothermal modelling by combining a model for heat, vapour and liquid transport in walls with a BES model. In these studies, the interactions between exterior and interior environments via heat and moisture transfers in building components were investigated as well as interior moisture buffering by building components.

Some of these interactions are not of great concern for recent wall configurations, such as well-insulated walls with air cavity and vapour retarder inside, walls with impermeable siding or sheathing, etc. On the other hand, in historic buildings in Europe, solid masonry systems have often been used for outer walls, without the installation of an adequate air space, insulation and/or vapour retarder, allowing a strong hygrothermal interaction between exterior and interior via the heat and moisture transfer in the walls. For such walls, the absorption of wind-driven rain (WDR) loads may result in a significant moisture flow towards the interior surface and environment, potentially yielding mould growth at inside wall surfaces, increased indoor humidity and/or increased heat transmission. The WDR load has however hardly been taken into account in previous whole building hygrothermal modelling. Therefore the influence of WDR loads on the whole building hygrothermal performance is particularly focused on in this paper.

Hall and Kalimeris $[9,10]$ is perhaps the first case in which the impact of WDR loads on the moisture content in walls is investigated numerically. Janssen et al. [4,11] and Blocken et al. [12] recently formulated the implementation of numerically determined WDR loads as boundary condition in the heat and moisture transfer analysis in building enclosures, based on advanced numerical techniques of Computational Fluid Dynamics (CFD) [13,14]. Also Häupl et al. [15] numerically investigated the impact of the rain on the hygrothermal performance of the facade of the 'Rijksmuseum' in Amsterdam, the Netherlands. Furthermore Kumaraperumal et al. [16] showed an experimental and numerical analysis of WDR loads and the hygric response of the walls for a Scottish castle. However several topics related to the response of a wall to the driving rain load still need further investigation. Examples are durability issues of building facades, algae formation at exterior surfaces, the possible impact on mould growth at inside wall surfaces, and the impact on indoor climate and energy consumption. The answers to these questions do not only depend on the composition of the wall and the outside climate, but also on the building configuration, moisture buffering capacity of the interior, heat and moisture sources in the building, ventilation rate, etc. Furthermore, although the distribution of the WDR load, with an intensity often highest near the upper edges and the sides of building facades [14], is considered to have an important role in the hygrothermal performance of buildings, so far no quantitative investigation of the impact of such distributed WDR load has been performed on the whole building scale. Such multicausal problems can not be adequately dealt with via a component hygrothermal model, but do require whole building hygrothermal simulation. This paper presents an onset of such a study: the impact of the distributed WDR loads on the hygrothermal behaviour of the walls and the indoor environment of a tower building has been investigated.

In the first part of this paper, the methodology of the whole building simulation - with emphasis on the WDR simulation and the implementation of WDR loads in hygrothermal simulation of building components - is briefly presented. In the second part, the WDR load on the facade of a $4 \times 4 \times 10 \mathrm{~m}^{3}$ tower is numerically determined. Then the heat and moisture transfer in the brick walls and the hygrothermal conditions in the room are numerically investigated on a horizontal slice through the walls and interior environment at half the tower height. Finally the impact of WDR on the hygrothermal performance, mould growth potential, indoor climate and energy consumption is discussed.

\section{Methodology}

\subsection{Whole building modelling of heat and moisture transfer}

In this paper a whole building simulation is defined as the numerical simulation of coupled heat, air and 
moisture transfer in building components and building zones, with the aim of comprehensively investigating the durability of the components, and the indoor climate and energy consumption of the zones. First, outdoor air conditions are often assumed to be uniform in this kind of simulations. Note that the distribution of outdoor conditions can sometimes get rather large especially e.g. in a street canyon under a hot climate due to combined effects of solar gain and wind [17-18]. In such situation, a more precise approach by CFD [e.g. 19] can be useful. However because only a case study with a simple tower building under a cold climate is presented in this paper, such distribution is not considered. When "perfect mixing" of indoor air is also assumed, the whole building modelling of the interactions between exterior and interior climates via building components usually comprises: (1) the heat, air and moisture balance of the building zone(s); (2) the heat, air and moisture transfer in the building components; and (3) the boundary conditions for (1) and (2) and the coupling of (1) and (2). Because essential parts of the whole building simulation are widely known and used in this field and only simple case studies are presented in this paper, the reader is referred to e.g. [5-8] for a more general mathematical formulation of the whole building simulation. In the current study, the heat and moisture balances for the zone are expressed as:

$\rho c V \frac{\partial T_{i}}{\partial t}=Q_{\text {wall }}+Q_{\text {vent }}+Q_{\text {int ernal }}$

$\rho V \frac{\partial X_{i}}{\partial t}=W_{\text {wall }}+W_{\text {vent }}$

where $\rho$ is the density of the indoor air $\left(\mathrm{kg} / \mathrm{m}^{3}\right), c$ is the specific heat of the indoor air $(\mathrm{J} / \mathrm{kg}), V$ is the volume of the room $\left(\mathrm{m}^{3}\right), t$ is the time (s), $T_{i}$ is the temperature of the indoor air $(\mathrm{K}), X_{i}$ is the humidity ratio of the indoor air (kg/kg), $Q_{\text {wall }}$ and $W_{\text {wall }}$ are respectively the heat and moisture gain/loss (W and $\mathrm{kg} / \mathrm{s}$ ) of the entire wall surface, $Q_{\text {vent }}$ and $W_{\text {vent }}$ are respectively the heat and moisture gain/loss (W and $\mathrm{kg} / \mathrm{s}$ ) due to ventilation, $Q_{\text {internal }}$ is the internal heat gain/loss (W).

Also, the heat and moisture transfer equations in building components are expressed [e.g. 4] as:

$c_{h h} \frac{\partial T}{\partial t}+c_{h m} \frac{\partial p_{c}}{\partial t}=\nabla\left(k_{h h} \nabla T+k_{h m} \nabla p_{c}\right)$

$c_{m m} \frac{\partial p_{c}}{\partial t}+c_{m h} \frac{\partial T}{\partial t}=\nabla\left(k_{m m} \nabla p_{c}+k_{m h} \nabla T\right)$

where $p_{c}$ and $T$ are capillary pressure $(\mathrm{Pa})$ and temperature $(\mathrm{K})$ respectively, $c_{h h}\left(\mathrm{~J} / \mathrm{m}^{3} \mathrm{~K}\right)$ and $c_{h m}\left(\mathrm{~J} / \mathrm{m}^{3} \mathrm{~Pa}\right)$ are the heat storage coefficients, $c_{m m}\left(\mathrm{~kg} / \mathrm{m}^{3} \mathrm{~Pa}\right)$ and $c_{m h}\left(\mathrm{~kg} / \mathrm{m}^{3} \mathrm{~K}\right)$ are the moisture storage coefficients, $k_{h h}$ $(\mathrm{W} / \mathrm{mK})$ and $k_{h m}(\mathrm{~W} / \mathrm{mPa})$ are the thermal conductivity due to the $T$-gradient and the $p_{c}$-gradient respectively, and $k_{m m}$ (s) and $k_{m h}(\mathrm{~kg} / \mathrm{msK})$ are the moisture permeability due to gradients in $p_{c}$ and $T$ respectively. Note that the air transfer in building components has hardly been considered in previous onsets of whole building simulation models and will also not be dealt with in the current study.

\subsection{Boundary conditions at wall surfaces}

The heat and moisture transfers in building components are coupled with the heat and moisture balances for the building zone by boundary conditions for heat and moisture exchange at inside wall surfaces of the zones, commonly using heat and moisture transfer coefficients. Thus the moisture and heat fluxes $g_{m, i}$ and $g_{h, i}$ at the inside wall surface are expressed as:

$$
\begin{aligned}
& g_{m, i}=-\beta_{i}\left(p_{i}-p_{s, i}\right) \\
& g_{h, i}=-\alpha_{t, i}\left(T_{i}-T_{s, i}\right)-\beta_{i}\left(c_{v} T_{s, i}+L_{v}\right)\left(p_{i}-p_{s, i}\right)
\end{aligned}
$$

Here, $\beta_{i}(\mathrm{~s} / \mathrm{m})$ is the moisture transfer coefficient at the inside wall surface; $p_{i}$ and $p_{s, i}(\mathrm{~Pa})$ are the vapour pressure of the indoor air and at the inside wall surface respectively; $\alpha_{t, i}\left(\mathrm{~W} / \mathrm{m}^{2} \mathrm{~K}\right)$ is the total heat transfer coefficient at the inside wall surface; $T_{i}$ and $T_{s, i}(\mathrm{~K})$ are the temperature of the indoor air and at the inside wall surface; $c_{v}(\mathrm{~J} / \mathrm{kgK})$ is the specific heat of the vapour water; and $L_{v}(\mathrm{~J} / \mathrm{kg})$ is the heat of vaporisation.

Similarly, the heat and moisture transfer equations in building components require boundary conditions at the exterior side: outdoor air temperature and humidity, cloudiness, solar and diffuse radiation, convective heat and moisture transfer coefficient, and wind-driven rain rainfall intensity. Without splashing, bouncing, runoff of rain at building facades, the moisture flux at the outside wall surface $g_{m, e}\left(\mathrm{~kg} / \mathrm{m}^{2} \mathrm{~s}\right)$ as boundary condition of the heat and moisture transfer equations in building components can be expressed as [e.g. 4]:

$g_{m, e}=-\beta_{e}\left(p_{e}-p_{s, e}\right)-I_{W D R}$ 
Here, $\beta_{e}(\mathrm{~s} / \mathrm{m})$ is the moisture transfer coefficient at the outside wall surface; $p_{e}$ and $p_{s, e}(\mathrm{~Pa})$ are the vapour pressure of the outdoor air and at the outside wall surface respectively; and $I_{W D R}\left(\mathrm{~kg} / \mathrm{m}^{2} \mathrm{~s}\right)$ is the WDR load. Note the assumption that the WDR load $I_{W D R}$ is temporally averaged over a certain period (usually one hour) [4].

The heat flux at the outside wall surface $g_{h, e}\left(\mathrm{~W} / \mathrm{m}^{2}\right)$ that takes into account the WDR enthalpy can be expressed as:

$g_{h, e}=-\alpha_{c e}\left(T_{e}-T_{s, e}\right)-S_{e}-\beta_{e}\left(c_{v} T_{s, e}+L_{v}\right)\left(p_{e}-p_{s, e}\right)-c_{l} T_{W D R} I_{W D R}$

Here, $\alpha_{c, e}\left(\mathrm{~W} / \mathrm{m}^{2} \mathrm{~K}\right)$ is the convective heat transfer coefficient at the outside wall surface; $T_{e}$ and $T_{s, e}(\mathrm{~K})$ are the temperature of the outdoor air and at the outside wall surface; $S_{e}\left(\mathrm{~W} / \mathrm{m}^{2}\right)$ is the heat flux due to radiative heat exchange between the surface position considered and all the surroundings; $c_{l}(\mathrm{~J} / \mathrm{kgK})$ is the specific heat of the liquid water; and $T_{W D R}$ is the temperature of WDR, which is assumed equal to $T_{e}$ in the simulations of this paper.

When the wall surface is saturated and moisture is still supplied, the boundary condition for $p_{c}$ can be given by the following equation instead of Eq. (7).

$p_{c}\left(x_{s}\right)=0$

Similarly, $g_{h}$ is also expressed by the following equations instead of the Eq. (8):

$g_{h, e}=-\alpha_{c e}\left(T_{e}-T_{s}\right)-S_{e}-\beta_{e}\left(c_{v} T_{s}+L_{v}\right)\left(p_{e}-p_{s}\right)-c_{l} T_{W D R}\left(I_{W D R}-g_{\text {runoff }}\right)$

Here, $g_{\text {runoff }}\left(\mathrm{kg} / \mathrm{m}^{2} \mathrm{~s}\right)$ is the runoff of the excess water at the outside wall surface due to both WDR loads and/or surface condensation. The excess water is ignored for the remainder of the simulation.

\subsection{WDR load on building facades}

The WDR load $I_{W D R}\left(\mathrm{~kg} / \mathrm{m}^{2} \mathrm{~s}\right)$ at building facades can be obtained by multiplying the horizontal rainfall intensity $I_{h}\left(\mathrm{~kg} / \mathrm{m}^{2} \mathrm{~s}\right)$ by the global catch ratio $\eta(-)[14]$ :

$I_{W D R}=I_{h} \times \eta\left(\theta, U_{r e f}, I_{h}\right)$

where $\eta$ is a function of the angle $\theta\left(^{\circ}\right)$ between reference wind direction and orientation of the wall, reference wind speed $U_{\text {ref }}(\mathrm{m} / \mathrm{s})$ and $I_{h}$, all obtained from meteorological data. $\eta$ can be obtained from measurements [20-22], empirical relations [20] or numerical simulations [13,14]. Note that detailed values of $\eta$ can only be obtained by numerical simulation, because the number of WDR gauges on facades is usually limited in measurements and empirical formula can only allow a rough estimate of WDR. For the methodology and a discussion of the accuracy of such numerically determined catch ratios the reader is referred to Blocken and Carmeliet [14] and Abuku et al. [23]. The difference between determined WDR load and the actual moisture load on the surface, due to the splashing and bouncing of raindrops, is discussed in Abuku et al. [24], based on numerical and experimental investigations. Note that the evaporation of multiple drops can differ from the evaporation that happens at a surface to which an averaged moisture flux is loaded. Such aspect of WDR loads on porous building walls is discussed by Abuku et al. [24]. Although it is necessary to take into account this aspect for a more detailed study, Eq. (11) is needed to make the hygrothermal simulation feasible at this moment.

\section{Building configuration, climate data and different calculation steps}

The current study focuses on the hygrothermal response of a $4 \times 4 \times 10 \mathrm{~m}^{3}$ tower with brick walls of $29 \mathrm{~cm}$ thickness taking into account the WDR load on the facades. Fig. 1 shows the configuration of the tower. Although the dimension of $4 \times 4 \times 10 \mathrm{~m}^{3}$ is rather small as building scale, this was adopted due to limits in computer capacity. Also the climate data of Essen, Germany, are used as trial data. The daily averaged climate data over the year is shown in Fig. 2. Note that hourly climate data were used in the simulations of this paper.

First, WDR loads on the facades of this tower are numerically determined by CFD and particle tracking simulations $[13,14]$. As a second step, the hygrothermal response of the first floor (3.5 to $6.5 \mathrm{~m}$ above the ground) is analysed. Because of limits in computer capacity, the analysis is performed on a 2-dimentional horizontal slice of the walls and the room $\left(4 \times 4 \mathrm{~m}^{2}\right)$ (see Fig. 1). WDR loads are vertically averaged to obtain representative WDR loads for vertical segments from 3.5 to $6.5 \mathrm{~m}$ above the ground. Thus it is assumed that the rain load on this part is vertically uniform and thus the vertical distribution of heat and moisture in the walls of this part is also uniform. Note that although masonry systems usually consist of brick and mortar, it is commonly assumed as a homogeneous isotropic material. This is also 
done in the current study. This may affect the penetration rate of rain into the wall and thus have some influence on the results obtained in section 5 .

\section{Numerical quantification of WDR loads}

The catch ratio for the facades of the $4 \times 4 \times 10 \mathrm{~m}^{3}$ tower was calculated with the method of Blocken and Carmeliet [14].

As a first step, the simulation of the airflow field was performed by CFD. The detailed condition of this CFD simulation is described in Abuku et al. [24]. Second, the trajectories of raindrops with a diameter of $0.3,0.4,0.5,0.6,0.7,0.8,0.9,1.0,1.2,1.4,1.6,1.8,2.0,3.0,4.0,5.0$ and $6.0 \mathrm{~mm}$ were simulated for 5 reference wind speeds $(2,4,6,8$ and $10 \mathrm{~m} / \mathrm{s})$. Then the specific catch ratio was calculated based on the trajectory of raindrops, and the specific catch ratio data were integrated into the catch ratio making use of Best's raindrop size distribution [25].

As an example Fig. 3 shows the global catch ratio distributions for 3 horizontal rainfall intensities (0.1 $\mathrm{mm} / \mathrm{h}, 1 \mathrm{~mm} / \mathrm{h}$ and $10 \mathrm{~mm} / \mathrm{h}$ ) and for 2 wind velocities $(2 \mathrm{~m} / \mathrm{s}$ and $8 \mathrm{~m} / \mathrm{s}$ ) perpendicular to the facade. While the catch ratio only has a small dependency on the rainfall intensity, it strongly depends on the reference wind speed. When looking at the spatial distribution, the rain load is highly concentrated near the top of the facade especially for small horizontal rainfall intensities.

The catch ratio $\eta$ for a wind perpendicular to the facade was vertically averaged from 3.5 to $6.5 \mathrm{~m}$ above the ground. The results at the edge and the centre on the facade are shown in Fig. 4 (a) and (b).

When the wind is oblique to the facade, the cosine projection method [11] was adopted for the calculation of the catch ratio. When the angle $\theta$ between the normal to the facade and the wind direction is obtuse, the catch ratio on that facade is assumed zero. Therefore WDR load $I_{W D R}$ is expressed as:

$$
\begin{aligned}
& -90^{\circ}<\theta<90^{\circ}: I_{W D R}\left(\theta, U_{r e f}, I_{h}\right)=I_{W D R}\left(0^{\circ}, U_{r e f} \times \cos \theta, I_{h}\right) \\
& -180^{\circ} \leq \theta \leq-90^{\circ}, 90^{\circ} \leq \theta \leq 180^{\circ}: I_{W D R}\left(\theta, U_{r e f}, I_{h}\right)=0
\end{aligned}
$$

Note however that the cosine projection method is less reliable when the angle $\theta$ gets close to 90 degree [26]; but, because the catch ratio is very low for such angles, the error is of low importance from the point of view of heat and moisture transfer simulation in building components [11].

WDR intensities at the exterior wall surfaces with an interval of $0.2 \mathrm{~m}$ were calculated by combining the hourly climate data and the catch ratio data determined above (the catch ratio data at the edge and the centre on the facade are shown in Fig. 4 (a) and (b)), depending on wind speed, wind direction, horizontal rainfall intensity, and orientation of the building facades. Note that although the use of hourly data of wind and rain can sometimes compromise the accuracy of the WDR calculation [27], only hourly data are available here. The time course of their cumulative amounts at the edges and the centres of the walls is shown in Fig. 4 (c) and (d). Due to the prevailing SW wind direction in Essen, the WDR load is concentrated at the west- and south-facing facades and some WDR is loaded onto the north-facing facades, while almost no WDR reaches the east-facing facade. For each facade, the WDR load is the highest at the edges of the wall and the lowest at the centre of the wall.

\section{Numerical assessment of the WDR impact on mould growth, indoor climate, and energy consumption}

\subsection{Condition of numerical analyses}

In this section, three simulations of the heat and moisture balances of the room are conducted. In all simulations, the indoor temperature is kept constant at $20^{\circ} \mathrm{C}$, and a constant ventilation rate of $0.5 \mathrm{ACH}$ is imposed. In all simulations, the indoor and outdoor climates thus at least interact via the ventilation air. The differences between the three simulations concern the interaction between the walls and the room and the application of WDR. In case (1), the full interaction between the heat and moisture in the walls and the room, with application of WDR at the exterior boundaries, is simulated. In case (2), similarly the full interaction is maintained, but no WDR is applied at the exterior boundaries $\left(I_{W D R}=0\right)$. In case (3), no walls-room interaction is considered $\left(Q_{\text {wall }}=0\right.$ and $\left.W_{\text {wall }}=0\right)$ : the indoor and outdoor climates are linked solely through the ventilation air. Case (3) purely shows the ventilation effects on the heat and moisture balance in the room. The comparison of case (3) and (2) shows the importance of the hygric inertia. The comparison of case (2) and (1) shows the WDR impact.

Numerical simulations are carried out on the 2-dimensional horizontal slice of the construction $(4 \times 4$ $\mathrm{m}^{2}$, wall thickness $29 \mathrm{~cm}$ ) (see Fig. 1). The room temperature and humidity are assumed spatially uniform 
in the room, employing the "perfect mixing" assumption, and the indoor humidity is calculated in all three cases. The heat and moisture transfer in the horizontal slice of the brick walls is analysed in case (2) and (3) with a FEM method [4].

The horizontal slice of the walls is discretised with 18360 nodes based on grid sensitivity analyses, resulting in 18000 linear triangular elements. Given the perfect mixing assumption, one node is used to represent the indoor environment. The material properties of brick are taken from the benchmark 'Response analysis' of the European project HAMSTAD [28]. Note that the capillary moisture content and water absorption coefficient of brick are $147 \mathrm{~kg} / \mathrm{m}^{3}$ and $0.14 \mathrm{~kg} / \mathrm{m}^{2} \mathrm{~s}^{1 / 2}$ respectively. The short wave absorptivity and long-wave emissivity of brick are taken at 0.5 and 0.9 respectively. Note also the assumption that no hysteresis of material properties occurs.

The initial temperature and $\mathrm{RH}$ in the walls are set at $20{ }^{\circ} \mathrm{C}$ and $50 \%$ respectively and the initial indoor RH is set at $50 \%$.

The yearly climate data record of Essen of Germany shown in Fig. 2 is used. The cloudiness is kept constant at 0.6. The WDR loads calculated in the previous chapter (the data at the edges and centres of the facades are given in Fig. 4 (c) and (d)) are used in the current simulation. The catch ratio for the positions of the nodes at the exterior wall surfaces is calculated by a linear interpolation of the given values for the two neighbouring positions which are calculated as described in section 4 with an interval of $0.2 \mathrm{~m}$.

Surface transfer coefficients at the outside wall surfaces $\alpha_{c, e}$ and $\beta_{e}$ are kept constant at $20 \mathrm{~W} / \mathrm{m}^{2} \mathrm{~K}$ and $1.54 \times 10^{-7} \mathrm{~s} / \mathrm{m}$ respectively. In reality, these values depend on wind speed, wind direction and position on the facade, and they may have a significant influence on the moisture response [11]. For instance a larger value is expected at the edge of the wall compared to the centre of the wall when the main stream of the wind is facing the facade. However, because the exact spatial and temporal variation of the values is unknown, constant values (independent of space and time) are adopted in the current simulations.

At the inside wall surfaces, transfer coefficients are based on the measurement results of Rei $\beta$ and Erhorn [29], which takes their spatial distribution into account. The total heat transfer coefficient $\alpha_{t, i}\left(x_{i}\right)$ $\left(\mathrm{W} / \mathrm{m}^{2} \mathrm{~K}\right)$ at a position $x_{i} \mathrm{~m}$ away from the edge of the inside wall surface is expressed by:

$\alpha_{t, i}\left(x_{i}\right)=\alpha_{t, i, \text { centre }}\left\{1-\left(1-\frac{\alpha_{t, i, \text { edge }}}{\alpha_{t, i, \text { centre }}}\right) \exp \left(-3 \frac{x_{i}}{d}\right)\right\}$

with $\alpha_{t, i, c e n t r e}$ the total heat transfer coefficient at the centre of the inside wall surfaces $\left(\mathrm{W} / \mathrm{m}^{2} \mathrm{~K}\right) ; \alpha_{t, i, e d g e}$ the total heat transfer coefficient at the edges of the inside wall surfaces $\left(\mathrm{W} / \mathrm{m}^{2} \mathrm{~K}\right) ; d$ the wall thickness $(\mathrm{m})$ $(=0.29 \mathrm{~m})$. In the current simulations $\alpha_{t, i, c e n t r e}$ and $\alpha_{t, i, e d g e}$ are arbitrarily kept constant at $8 \mathrm{~W} / \mathrm{m}^{2} \mathrm{~K}$ and 6 $\mathrm{W} / \mathrm{m}^{2} \mathrm{~K}$ respectively [29]. The values in reality might be even smaller than these values [29,30], especially when e.g. furniture is placed against the wall or when the indoor air is extremely stagnant. The moisture transfer coefficient at the inside wall surfaces $\beta_{i}$ is determined from half the total heat transfer coefficient $\alpha_{t, i}\left(x_{i}\right) / 2$ (to exclude the radiation effects), by use of the Lewis relation.

Fig. 5 plots three spatially distributed conditions: the total heat transfer coefficient at the interior wall surfaces and the cumulative WDR and solar gain at the exterior wall surfaces over the year. The next section will discuss the combined hygrothermal effects of the geometry of the corners of the walls and the spatially distributed conditions in this study: the three conditions presented in Fig. 5 and the moisture transfer coefficient at the inside wall surfaces.

\subsection{Result and discussion}

\subsubsection{Response of walls}

In this part, only the simulation results with the WDR loads (case (1)) are shown, because in the simulation results without WDR load no noticeable increase of moisture content at the inside wall surfaces was observed. Thus the response of walls shown in this part can be considered to be the impact of the WDR loads.

The time evolution of the moisture content at the inside wall surfaces over the year is shown in Fig. 6 . Fig. 6 (a) and (b) show results at the four edges and those at the centres respectively. Comparison of Fig. 6 (a) and (b) shows that, although only small differences in WDR load between the edges and the centres occur as shown in Fig. 4 (c) and (d), large differences in moisture response are found. The reason of this difference is fourfold. First, WDR intensity at the edges is higher than the one at the centres in the current study. Secondly, the corners of the walls are facing to outdoor environments at two sides and are thus more exposed to WDR loads than the centres. Third, a lower evaporation rate occurs at the edges of the inside wall surfaces, because of the geometry and the lower heat and moisture transfer coefficients at the 
inner edges. Finally, because the corners of the walls are facing to outdoor environments at two sides, the exterior wall surface temperature at the edges is more susceptible to outdoor air temperature than the one at the centres. Also outdoor air temperature (see Fig. 2 (a)) is often lower than indoor air temperature $\left(20^{\circ} \mathrm{C}\right)$. These two facts contribute to a lower evaporation rate at the edges than the one at the centres. Note however, that the current simulation assumes the outer surface film coefficient to be spatially and temporally constant, though in reality it may vary in space and time. In reality this coefficient may be higher at the edges than at the centre, which may reduce the impact of WDR at the edge.

Looking at Fig. 6 (a), a noticeable increase of the moisture contents at the four edges of the inside wall surfaces is observed in December due to WDR loads, the most significant at the north-west and south-west edge. The moisture content shows a much smaller increase during the summer than during the winter period as a result of increased drying potential caused by the solar and diffuse radiation on the outside surface (see Fig. 2 (c) and (d)). During and after some rain events, especially during the spring and the autumn, WDR does not influence the moisture content at the inside wall surfaces. Similar explanations can be given to Fig. 6 (b).

Fig. 7 illustrates the spatial distribution of the moisture content over the walls at the beginning (6:00, $5 / 12)$, some days after the beginning $(0: 00,13 / 12)$ and at the end $(0: 00,15 / 3)$ of the first period with strong WDR loads (December to March) which caused significant increases of moisture content at inside wall surfaces as explained above. Fig. 7 (a) shows the absorption process of distributed strong WDR at the west facade and some WDR at the south facade. While the north-west corner shows an approximately one-dimensional absorption process, two-dimensional absorption is seen near the south-west corner as a result of the combined WDR loads from both west and south. Fig. 6 (b) shows that a region of very high moisture content reached to the distance of almost double the thickness of the walls for the current case. This is a consequence of the combined effects of the geometric effect of corners of the west facade, distributed WDR loads at the exterior sides and distributed transfer coefficients at the interior sides. At this moment, only a small edge effect is seen within two metres around the centre of the west facade. Finally Fig. 7 (c) shows that at the end of this period, the effect only remained longer at and near the south-west corner exposed to strong WDR loads from both west and south during the period (see Fig. 4 (c) and (d)), regardless of a larger drying potential due to solar gains at the south facade.

\subsubsection{Impact on mould growth}

One of the advantages of whole building simulations is the possibility of more accurately assessing the risk of mould growth at inside wall surfaces, as the surface temperature and relative humidity strongly reflects the interaction between zone and component. In this part, the simulation results without WDR load (case (2)) are compared with the one with the WDR loads (case (1)) and the impact of the WDR loads on mould growth at inside wall surfaces is discussed.

Fig. 8 shows the daily averaged temperature and relative humidity at the edge (facing south-west) and centre (facing south) of the inside wall surfaces on the graphs of generalised isopleths of the spore germination time of the fungus mould for substrate category I [31]. Fig. 8 (a) and (b) show the results of the simulation without WDR load and Fig. 8 (c) and (d) show the results with the WDR loads. The same plots can be applied to the mycelium growth rate, with a similar ensuing discussion. Although brick is considered to be a category II substrate, the category I isopleths for are adopted here as worst case scenario. If the relative humidity for a given temperature is below the line of $\infty$ days, no biological activity is expected. Note that, when the RH is too high (e.g. RH > at least $96 \%$ [31]), the mould may not grow but can still exist.

Each figure compares seasonal risks. Analysing the risk without taking into account WDR (see Fig. 8 (a) and (b)), no mould growth is expected; but, when the WDR is taken into account, looking at Fig. 8 (c) and (d), a serious risk on mould growth can be expected, mainly in summer and winter, with a more serious risk in summer than in winter. The comparison of the results of the simulation with the WDR loads and those without WDR shows that the impact of the WDR on the mould growth at the inside wall surfaces is significant.

Comparing Fig. 8 (c) and (d), a wider variation of surface temperatures is seen at the edge than at the centre and the surface temperatures are averagely lower at the edge than at the centre. The reason of this difference is that the surface temperature at the edge is more influenced by the outdoor conditions.

When the variations and criteria of temperature and relative humidity are considered together, it is concluded that the criterion of relative humidity for mould growth is more severe than that of temperature for the current case. 


\subsubsection{Impact on indoor climate and energy consumption}

In this part, the three simulations are compared to show impacts of the WDR loads, moisture buffering effects of the walls and ventilation effects.

The evolution with time of the indoor RH of the 3 cases over the year and an excerpt of March are shown in Fig. 9. Comparing the simulation results without WDR load and those with only ventilation shows that the absorption and evaporation at the wall surfaces have a very small effect on indoor RH change (see Fig. 9 (b)), which is attributable to the low buffering potential of the ceramic brick in the hygroscopic region. On the other hand, the comparison of the results with the WDR loads to those without WDR load shows that the WDR causes significant increases of indoor relative humidity-compared to the situation without WDR-of up to $55 \%$ under the conditions considered, which is seen at 7th of March. The differences between the results with WDR load and those without WDR load are significant in winter and summer due to increases of the moisture content at the inside wall surfaces (see Fig. 6); it is less significant in spring and autumn.

Seasonal energy consumptions are given in Table 1, comparing the results of the 3 cases. Comparing the results without WDR (case (2)) to those with only ventilation (case (3)) shows that the energy consumption is mainly influenced by the heat flow through the (uninsulated) walls and that the ventilation is less important for energy consumption in the current conditions. When the results with the WDR loads (case (1)) are compared to those without WDR load (case (2)), the seasonal impact of the WDR on energy consumption under such conditions is estimated as $18.7 \%$ in winter (December, January and February); $3.8 \%$ in spring (March, April and May); $21.5 \%$ in summer (June, July and August); and $4.4 \%$ in autumn (September, October and November). The energy consumption for heating in summer is very low, though. Note that the current building configuration has no window, so that the impact on energy consumption in summer can be much smaller in reality due to solar gains. The annual impact is estimated as $11.8 \%$. The impact of the WDR is considered to be smaller when the ventilation rate is more important for energy consumption. Note that for hot climates the results may be different, since the energy consumption for cooling in summer periods may decrease through increased transmission losses to the outside [32], while the increased indoor RH due to rain loads may still increase the latent cooling loads and a rain load may increase the energy consumption for heating in winter.

These increases of indoor relative humidity and energy consumption due to WDR can be attributed to very high moisture contents at the entire inside surface of the walls as shown in Fig. 7 (b). Meanwhile, because the moisture content finally remains high only at and near the corner of the walls as seen in Fig. 7 (c), the increases are mainly attributable to high moisture content at and near the corner of the walls at the end of drying processes. This suggests that the local remedial renovation of building enclosures at their corners may be effective to prevent WDR impacts concerning not only mould growth potential but also indoor relative humidity and energy consumption at least for cold and humid climate.

\section{Conclusion}

An onset was given to whole building modelling and simulation of the interaction between interior and exterior climates via building enclosures with emphasis on wind-driven rain (WDR) and resulting liquid transfer. The impacts of WDR loads on the hygrothermal response of the brick walls, indoor climate, energy consumption and mould growth risk at the inside wall surfaces were investigated. The hygrothermal response of the solid brick walls and indoor climates of a historic tower building with distributed WDR loads was numerically analysed. The obtained relative humidity and temperature at the interior wall surfaces were combined with isopleths of generalised spore germination time of fungus mould. The results showed that WDR loads can have a significant impact on mould growth especially at the edges of the wall. Furthermore, for the case analysed, the simulations showed that WDR causes a significant increase of indoor relative humidity and energy consumptions for heating. Given the complexity of the phenomena under study and the assumptions in the proposed approach, the final results obtained here certainly require validation efforts. However the results at least show that such validation seems to be relevant to come to a better understanding of the performance of historic brick wall building under WDR loads in a cold and humid climate.

\section{Acknowledgements}

The results in this paper have been obtained within KUL OT/04/28, 'Towards a reliable prediction of the moisture stress on building enclosures', funded by the K.U.Leuven and IWT SBO 050154, 'Heat, air and 
moisture performance engineering: a whole building approach', funded by the Flemish Government. These financial supports are gratefully acknowledged.

\section{References}

[1] C. R. Pedersen, Combined heat and moisture transfer in building constructions, $\mathrm{PhD}$ thesis, Technical University of Denmark, 1990.

[2] H. M. Künzel, Verfahren zur ein- und zweidimensionalen Berechnung des gekoppelten Wärme- und Feuchtetransports in Bauteilen mit einfachen Kennwerten, PhD thesis, University of Stuttgart, 1994.

[3] J. Grunewald, Diffusiver und konvektiver Stoff- und Energietransport in kapillarporösen Baustoffen, $\mathrm{PhD}$ thesis, Technical University of Dresden, 1997.

[4] H. Janssen, B. Blocken, J. Carmeliet, Conservative modelling of the moisture and heat transfer in building components under atmospheric excitation, International Journal of Heat and Mass Transfer 50 (2007) 1128-1140.

[5] A. E. Nakhi, Adaptive construction modelling within whole building dynamic simulation. $\mathrm{PhD}$ thesis, University of Strathclyde, 1995.

[6] A. Holm, H. Kunzel, K. Seldbauer, The hygrothermal behaviour of rooms: combining thermal building simulation and hygrothermal envelope calculation, in: Proceedings of the Eighth International IBPSA Conference, Eindhoven, The Netherlands, August 11-14, 2003, pp. 499-505.

[7] C. Rode, M. Salonvaara, T. Ojanen, C. Simonson, K. Grau, Integrated hygrothermal analysis of ecological buildings. in: Proceedings of the 2nd International Conference on Building Physics, Leuven, Belgium, September 14-18, 2003, pp. 859-868.

[8] N. Mendes, R. Oliveira, G. Henrique dos Santos, Domus 2.0: a whole-building simulation program, in: Proceedings of the Eighth International IBPSA Conference, Eindhoven, The Netherlands, August 11-14, 2003, pp. 863-870.

[9] C. Hall, A. N. Kalimeris, Rain absorption and run-off on porous building surfaces, Canadian Journal of Civil Engineering 11 (1984) 108-111.

[10] C. Hall, A. N. Kalimeris, Water movement in porous building materials-V. Absorption and shedding of rain by building surfaces, Building and Environment 19 (1982) 13-20.

[11] H. Janssen, B. Blocken, S. Roels, J. Carmeliet, Wind-driven rain as a boundary condition for HAM simulations: Analysis of simplified modelling approaches, Building and Environment 42 (2007) 1555-1567.

[12] B. Blocken, S. Roels, J. Carmeliet, A combined CFD-HAM approach for wind-driven rain on building facades, Journal of Wind Engineering and Industrial Aerodynamics 95 (7) (2007) 585-607.

[13] E. C. C. Choi, Simulation of wind-driven-rain around a building, Journal of Wind Engineering and Industrial Aerodynamics 46\&47 (1993) 721-729.

[14] B. Blocken, J. Carmeliet, Spatial and temporal distribution of wind-driven rain on low-rise building, Wind and Structure 5 (5) (2002) 441-462.

[15] P. Häupl, J. Grunewald, U. Ruisinger, Hygrothermal 2-dimensional analysis of critical constructive details of the Rijksmuseum Amsterdam, Report, Institute for Building Climatology, Dresden University of Technology, Germany, 2005.

[16] A. Kumaraperumal, C. Sanders, P. Baker, CFD and hygrothermal modeling are compared with full-scale measurements to predict the fabric moisture contents due to wind-driven rain on a Scottish castle, International Report, IEA Annex 41, Task 3 - Boundary condition, A41-T3-UK-06-2, 2006.

[17] E. Bozonnet, R. Belarbi, F. Allard, Modelling solar effects on the heat and mass transfer in a street canyon, a simplified approach, Solar Energy 79(1) (2005) 10-24.

[18] K. Niachou, I. Livada, M. Santamouris, Experimental study of temperature and airflow distribution inside an urban street canyon during hot summer weather conditions-Part I: Air and surface temperatures, Building and Environment 43 (2008) 1383-1392.

[19] G. Carrilho da Graça, Q. Chen, L. R. Glicksman, L. K. Norford, Simulation of wind-driven ventilative cooling systems for an apartment building in Beijing and Shanghai, Energy and Buildings 34 (2002) 1-11.

[20] C. Sanders, Heat, air and moisture transfer in insulated envelope parts. IEA Annex 24, Final report Vol. 2, Task 2: Environmental conditions, Acco Leuven, 1996, pp. 75-85.

[21] B. Blocken, J. Carmeliet, High-resolution wind-driven rain measurements on a low-rise building - experimental data for model development and model validation, Journal of Wind Engineering and Industrial Aerodynamics 93 (2005) 905-928.

[22] K. Nore, B. Blocken, B. P. Jelle, J. V. Thue, J. Carmeliet, A database of wind-driven rain 
measurements on a low-rise test building in Norway, Building and Environment 42 (5) (2007) 2150-2165.

[23] M. Abuku, B. Blocken, K. Nore, J. V. Thue, J. Carmeliet, S. Roels, On the validity of numerical wind-driven rain simulation on a rectangular low-rise building under various oblique winds, Building and Environment (2008), in press (doi:10.1016/j.buildenv.2008.05.003).

[24] M. Abuku, H. Janssen, J. Poesen, S. Roels, Impact, absorption and evaporation of raindrops on building facades, Building and Environment (2008), in press (doi:10.1016/j.buildenv.2008.02.001).

[25] A.C. Best, The size distribution of raindrops, Quarterly Journal of the Royal Meteorological Society 76 (1950) 16-36.

[26] B. Blocken, J. Carmeliet, On the validity of the cosine projection in wind-driven rain calculations on buildings, Building and Environment 41 (2006) 1182-1189.

[27] B. Blocken, J. Carmeliet, On the errors associated with the use of hourly data in wind-driven rain calculations on building facades, Atmospheric Environment 41(11) (2007) 2335-2343.

[28] C.-E. Hagentoft, A. S. Kalagasidis, B. Adl-Zarrabi, S. Roels, J. Carmeliet, H. Hens, J. Grune-wald, M. Funk, R. Becker, D. Shamir, O. Adan, H. Brocken, K. Kumaran, R. Djebbar, Assessment method of numerical prediction models for combined heat, air and moisture transfer in building components: benchmarks for one-dimensional cases, Journal of thermal envelope and building science 27 (4) (2004) 327-352.

[29] J. Rei $\beta$, H. Erhorn, IEA Annex 14, Condensation and Energy, Final Report, Volume 1, Source Book, Leuven: Acco Uitgeverij, 1991, pp. 3.50-3.53.

[30] H. Hens, IEA Annex 14: Condensation and Energy, Journal of Thermal Insulation 15 (1992) 261-273.

[31] K. Sedlbauer, Vorhersage von Schimmelpilzbildung auf und in Bauteilen (Prediction of mould manifestation on and in building parts), PhD thesis, University of Stuttgart, 2001.

[32] S. Hokoi, Fundamental study of thermal characteristics of wet building walls, PhD thesis, Kyoto University, 1986.

Vitae

\section{Masaru Abuku}

Masaru Abuku is a Ph.D. candidate at the Laboratory of Building Physics, Department of Civil Engineering, Katholieke Universiteit Leuven (Belgium) since 2005. He graduated from the University of Tokyo, Japan, in 2003 on the master thesis "Chemical reaction of indoor air pollutants and the ventilation effect on it” and then was a Ph.D. candidate at Kyoto University, Japan, from 2003 until 2005. His current Ph.D. research concerns a comprehensive study of wind-driven rain loads on building enclosures, comprising raindrop impact on building facades, hygrothermal response of walls and impacts on building performances.

\section{Hans Janssen}

Hans Janssen earned his Ph.D. in 2002 at the Katholieke Universiteit Leuven with the thesis "The influence of soil moisture transfer on building heat loss via the ground". After a postdoctoral project at the same university, from 2003 till 2006, he currently works as assistant professor at the Department of Civil Engineering, Technical University of Denmark (Denmark). His research interests are the transfers of heat, air and moisture in whole buildings and building components and the related durability and sustainability issues, with a specific focus on numerical modelling.

\section{Staf Roels}

Staf Roels is a professor at the Laboratory of Building Physics, Department of Civil Engineering, Katholieke Universiteit Leuven (Belgium). He earned his Ph.D. at the Katholieke Universiteit Leuven in 2000 on the thesis “Modelling unsaturated moisture transport in heterogeneous limestone”. He lectures on building construction, performance based design and applied building physics. His research mainly focuses on moisture transport in porous building materials and the analysis of the hygrothermal behaviour and durability of building constructions. In his research he often combines refined numerical techniques with advanced experimental methods. 


\section{Table and Figure Captions}

Table 1. Seasonal and annual energy consumption.

Fig. 1. Configuration of the building and section under study. $d$ : thickness of the wall (m).

Fig. 2. Daily averaged climate data over the year. (a) Outdoor air temperature; (b) outdoor air relative humidity; (c) direct radiation; (d) diffuse radiation; (e) wind speed; (f) wind direction; (g) horizontal rainfall intensity.

Fig. 3. Catch ratio distribution on the facade $\left(4 \times 10 \mathrm{~m}^{2}\right)$ of the tower for 3 horizontal rainfall intensities and 2 wind speeds. The wind is perpendicular to the facade. In (a) and (d), $R_{h}=0.1 \mathrm{~mm} / \mathrm{h}$; in (b) and (e), $R_{h}=1 \mathrm{~mm} / \mathrm{h}$; in (c) and (f), $R_{h}=10 \mathrm{~mm} / \mathrm{h}$. In (a), (b) and (c), $U_{10}=2 \mathrm{~m} / \mathrm{s}$; in (d), (e) and (f), $U_{10}=8 \mathrm{~m} / \mathrm{s}$.

Fig. 4. (a,b) Catch ratio $\eta$ and (c,d) cumulative wind-driven rain (WDR) vertically averaged from 3.5 to $6.5 \mathrm{~m}$ above the ground at $(\mathrm{a}, \mathrm{c})$ the edges and $(\mathrm{b}, \mathrm{d})$ the centres on the facades.

Fig. 5. Spatial distribution of the total heat transfer coefficient at the interior wall surfaces, and the cumulative WDR and solar gain at the exterior wall surfaces over the year. The four vertical sections of the figure represent the facades facing to east, south, west and north respectively.

Fig. 6. Time evolution of moisture content at (a) the four edges and (b) the four centres of the inside wall surfaces.

Fig. 7. Spatial distribution of moisture content over the walls at (a) 6:00,5/12, (b) 0:00, 13/12 and (c) $0: 00,15 / 3$.

Fig. 8. Daily averaged temperature and humidity at the inside wall surfaces on the graph of generalised isopleths of the spore germination time (black solid lines) of the fungus mould for the substrate category I. (a) and (c) At the south-west facing edge of the wall; (b) and (d) at the south facing centre of the wall. In (a) and (b), no wind-driven rain load (WDR) is applied; in (c) and (d) wind-driven rain loads are applied.

Fig. 9. (a) Time evolution of indoor relative humidity of the 3 cases over the year and (b) an excerpt of March. In one case (only ventilation), indoor relative humidity was calculated taking into account only constant ventilation rate and indoor temperature; in another case (without WDR), the heat and moisture transfer was taken into account in addition of the conditions of the first case; and in the last case (with WDR), WDR was taken into account in addition to the conditions of the second case. 
Table 1. Seasonal and annual energy consumption

\begin{tabular}{c|l|l|r|r}
\hline & $\begin{array}{l}\text { (1) } \\
\text { ventilation + } \\
\text { evaporation/absorption } \\
\text { with WDR loads }\end{array}$ & $\begin{array}{l}\text { lentilation + } \\
\text { evaporation/absorption } \\
\text { without WDR load }\end{array}$ & $\begin{array}{l}\text { l3) } \\
\text { only ventilation }\end{array}$ & $\begin{array}{l}((1)-(2)) /(2) \times 100 \\
\text { (impact of WDR) }\end{array}$ \\
\hline winter & $1012.7 \mathrm{kWh}$ & $852.9 \mathrm{kWh}$ & $77.8 \mathrm{kWh}$ & $18.7 \%$ \\
\hline spring & $535.9 \mathrm{kWh}$ & $516.4 \mathrm{kWh}$ & $50.0 \mathrm{kWh}$ & $3.8 \%$ \\
\hline summer & $200.5 \mathrm{kWh}$ & $165.0 \mathrm{kWh}$ & $20.3 \mathrm{kWh}$ & $21.5 \%$ \\
\hline autumn & $485.2 \mathrm{kWh}$ & $464.7 \mathrm{kWh}$ & $43.6 \mathrm{kWh}$ & $4.4 \%$ \\
\hline annual & $2234.3 \mathrm{kWh}$ & $1999.0 \mathrm{kWh}$ & $191.7 \mathrm{kWh}$ & $11.8 \%$ \\
\hline
\end{tabular}




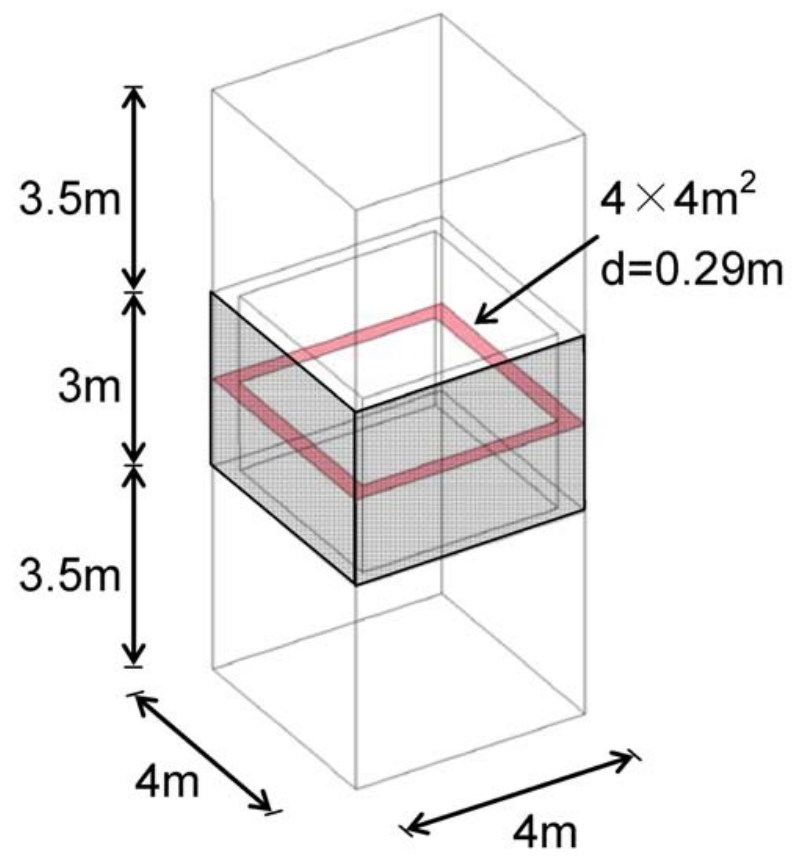

Fig. 1. Configuration of the building and section under study. $d$ : thickness of the wall (m). 
(a)

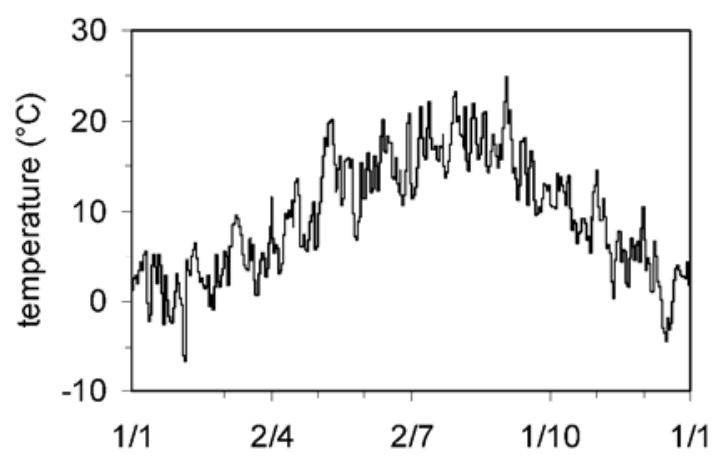

(c)

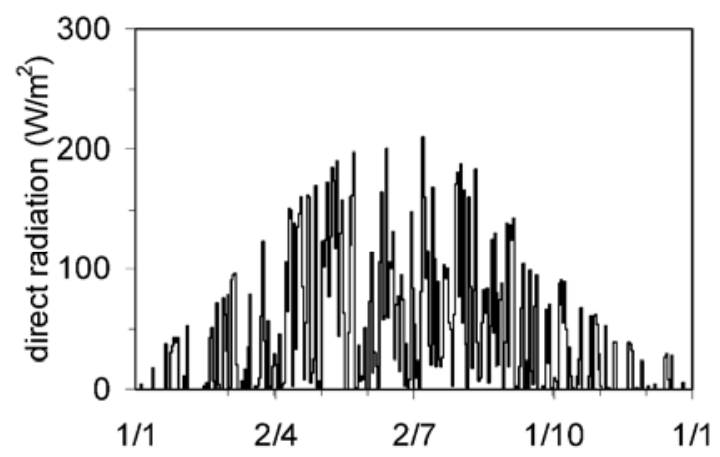

(e)

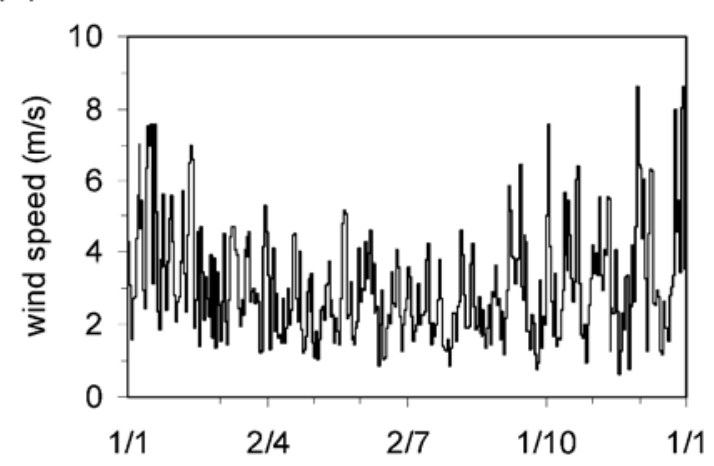

(g)

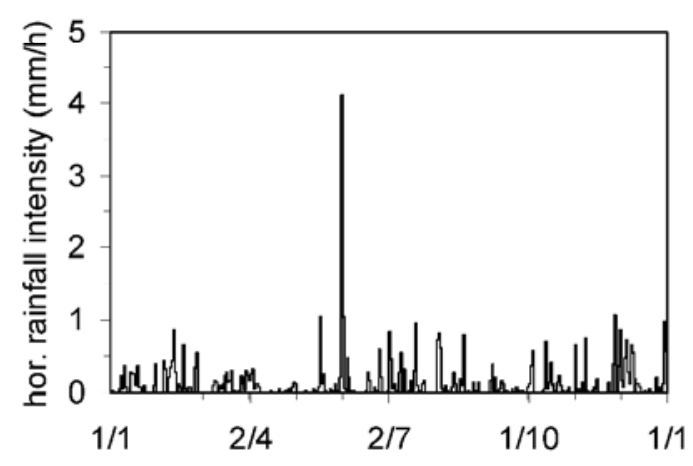

(b)

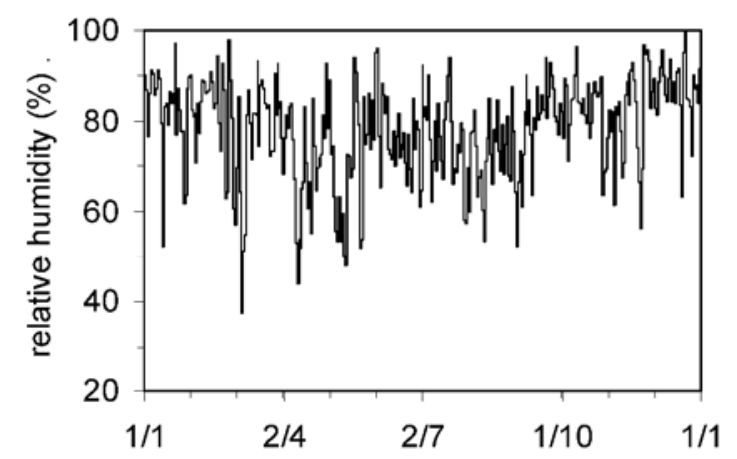

(d)

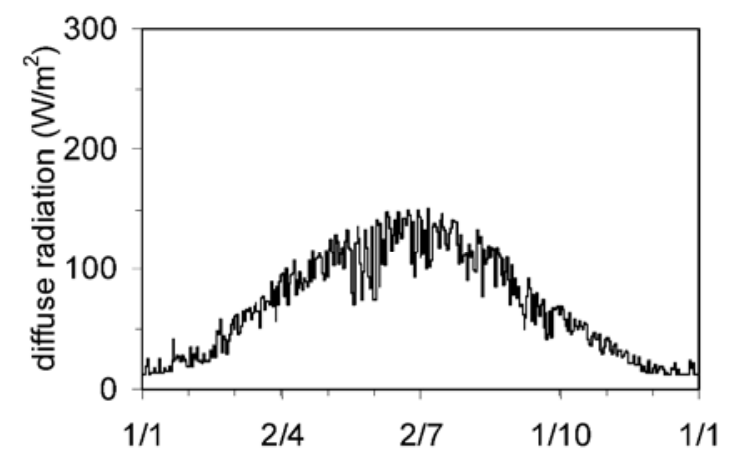

(f)

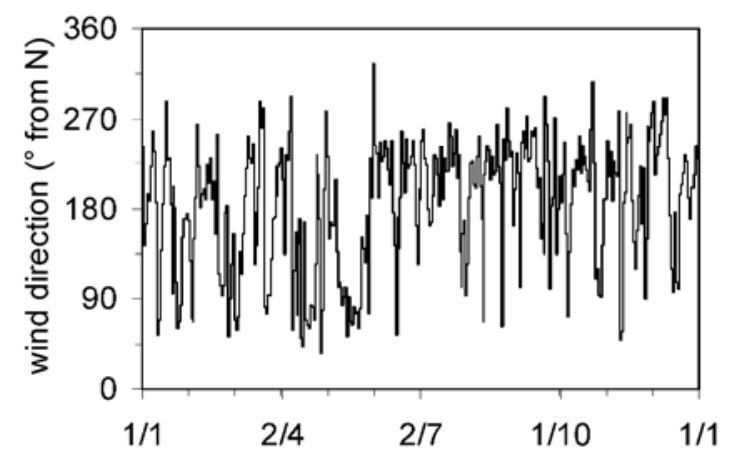

Fig. 2. Daily averaged climate data over the year. (a) Outdoor air temperature; (b) outdoor air relative humidity; (c) direct radiation; (d) diffuse radiation; (e) wind speed; (f) wind direction; (g) horizontal rainfall intensity. 
(a)

(b)

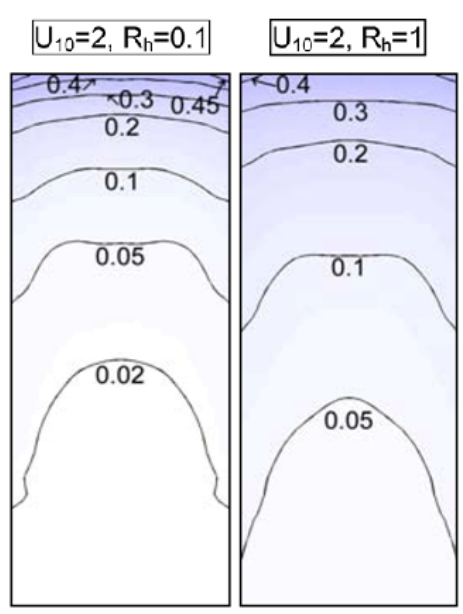

(c)
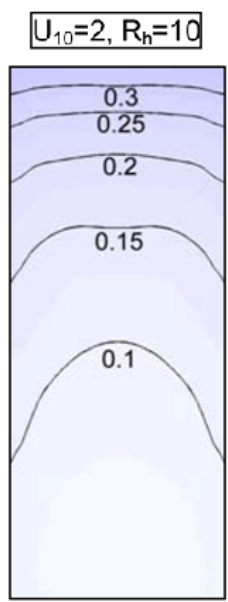

(d)

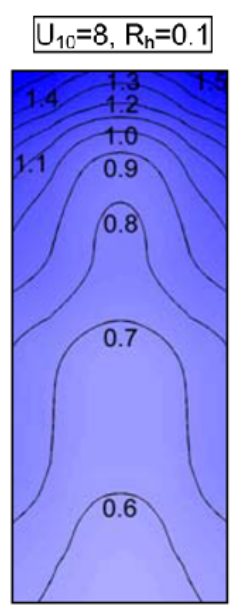

(e)

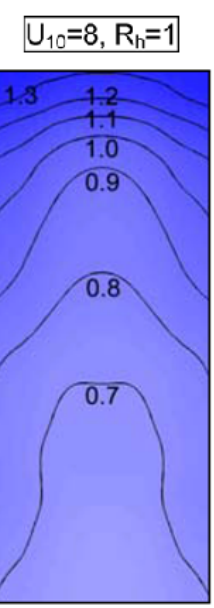

(f)

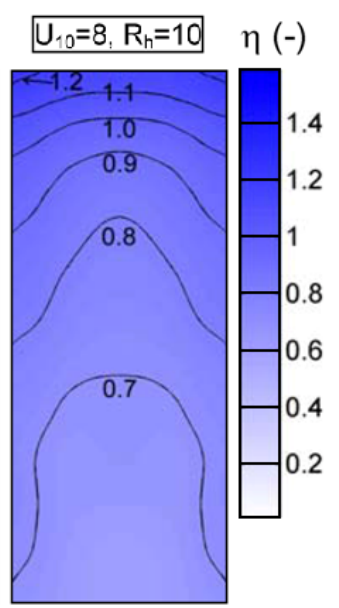

Fig. 3. Catch ratio distribution on the facade $\left(4 \times 10 \mathrm{~m}^{2}\right)$ of the tower for 3 horizontal rainfall intensities and 2 wind speeds. The wind is perpendicular to the facade. In (a) and (d), $R_{h}=0.1 \mathrm{~mm} / \mathrm{h}$; in (b) and (e), $R_{h}=1 \mathrm{~mm} / \mathrm{h}$; in (c) and (f), $R_{h}=10 \mathrm{~mm} / \mathrm{h}$. In (a), (b) and (c), $U_{10}=2 \mathrm{~m} / \mathrm{s}$; in (d), (e) and (f), $U_{10}=8 \mathrm{~m} / \mathrm{s}$. 
(a)

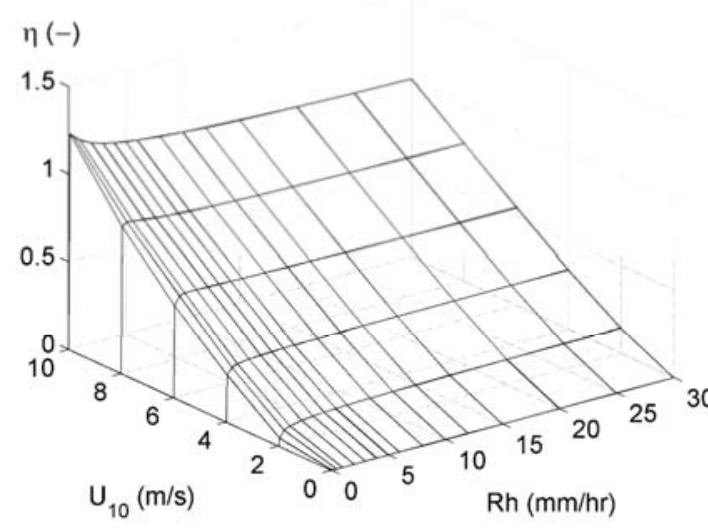

(c)

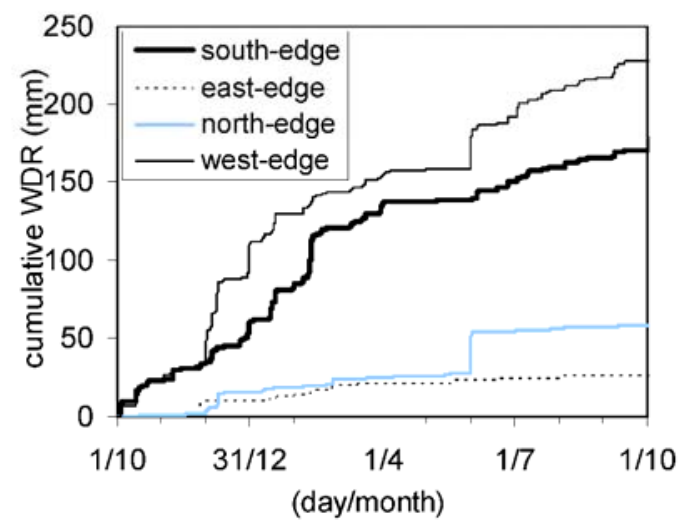

(b)

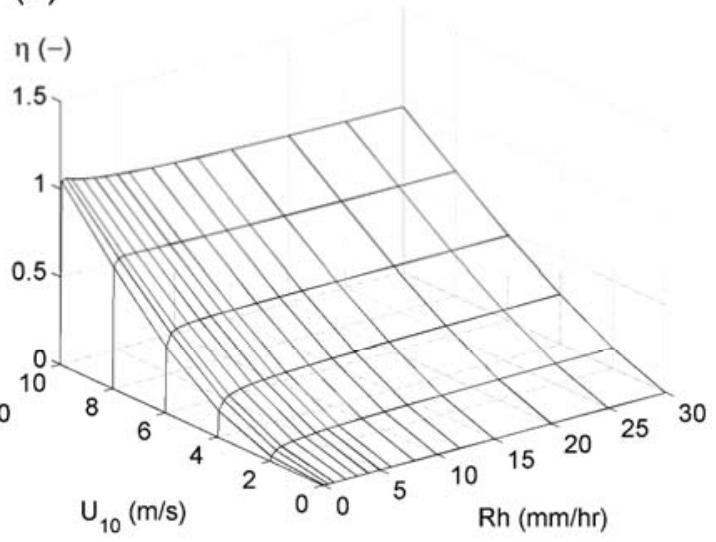

(d)

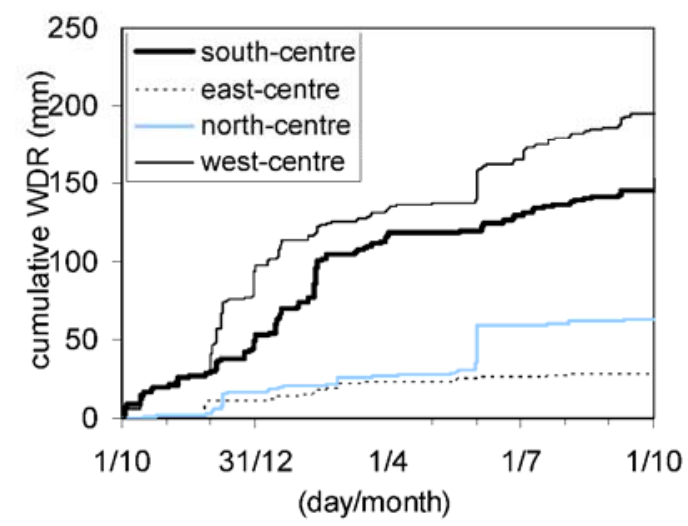

Fig. 4. (a,b) Catch ratio $\eta$ and (c,d) cumulative wind-driven rain (WDR) vertically averaged from 3.5 to $6.5 \mathrm{~m}$ above the ground at $(\mathrm{a}, \mathrm{c})$ the edges and $(\mathrm{b}, \mathrm{d})$ the centres on the facades. 


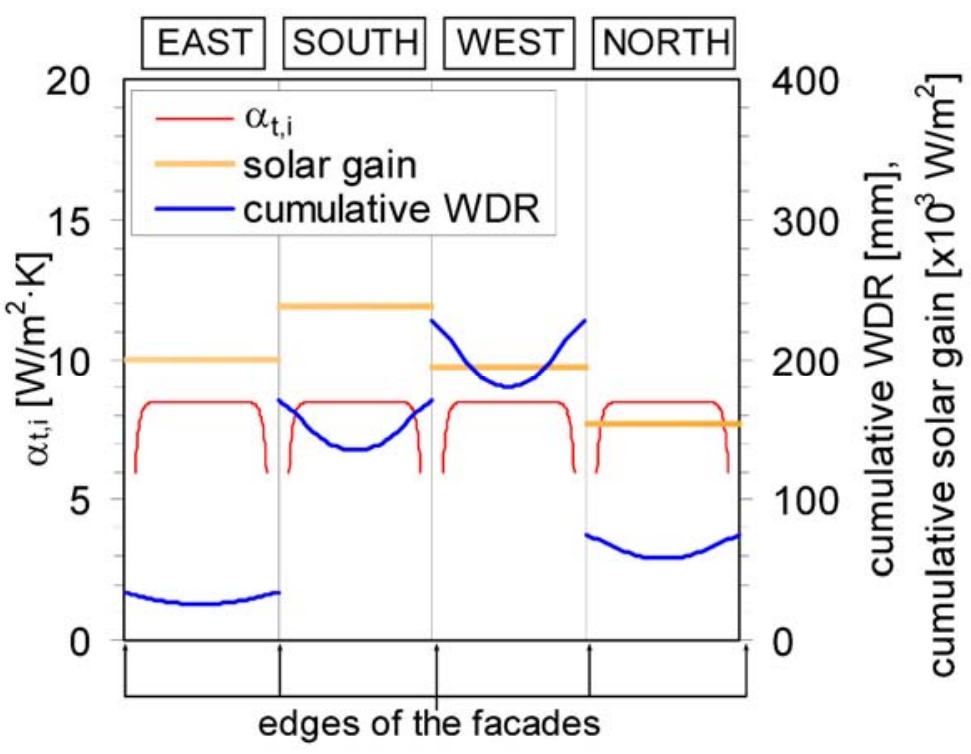

Fig. 5. Spatial distribution of the total heat transfer coefficient at the interior wall surfaces, and the cumulative WDR and solar gain at the exterior wall surfaces over the year. The four vertical sections of the figure represent the facades facing to east, south, west and north respectively. 
(a)

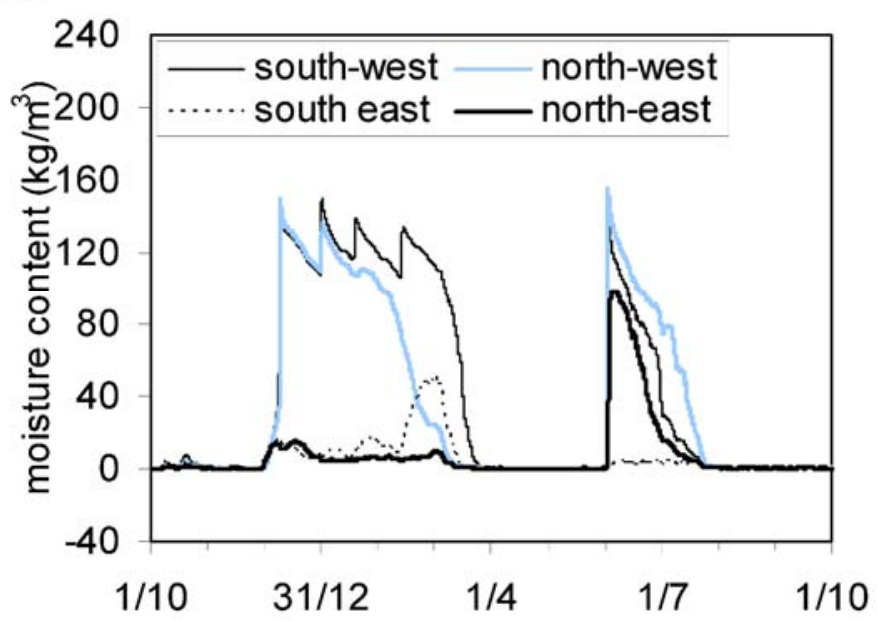

(b)

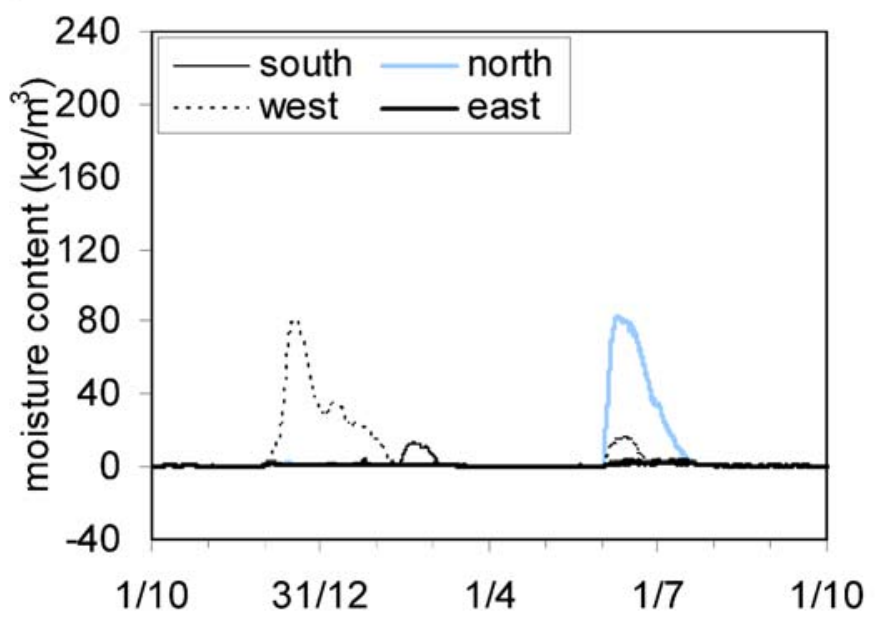

Fig. 6. Time evolution of moisture content at (a) the four edges and (b) the four centres of the inside wall surfaces. 
(a)

(b)

(c)
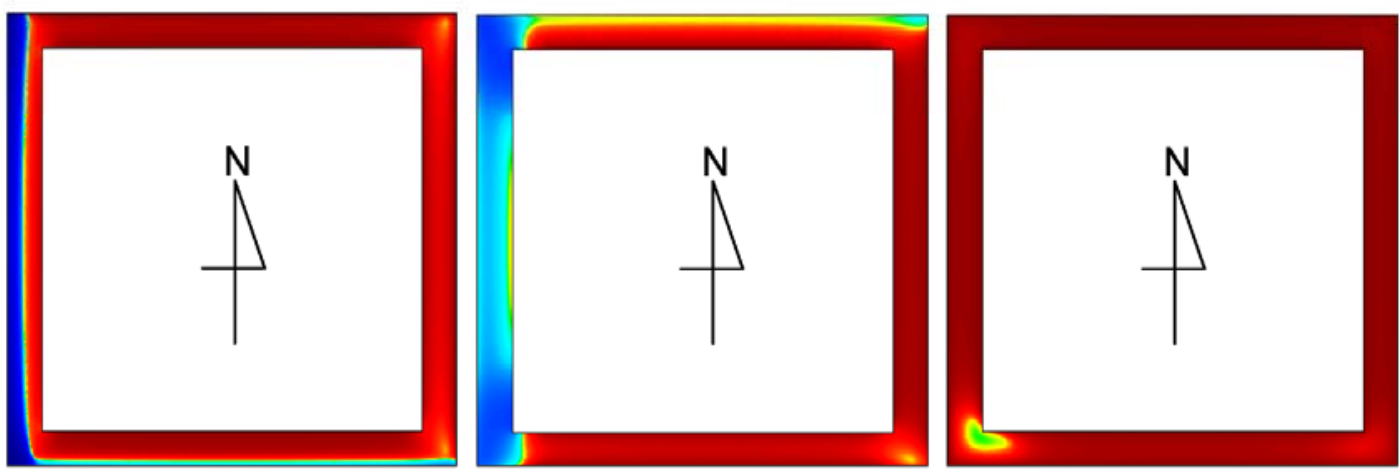

Fig. 7. Spatial distribution of moisture content over the walls at (a) 6:00, 5/12, (b) 0:00,13/12 and (c) $0: 00,15 / 3$. 
(a)

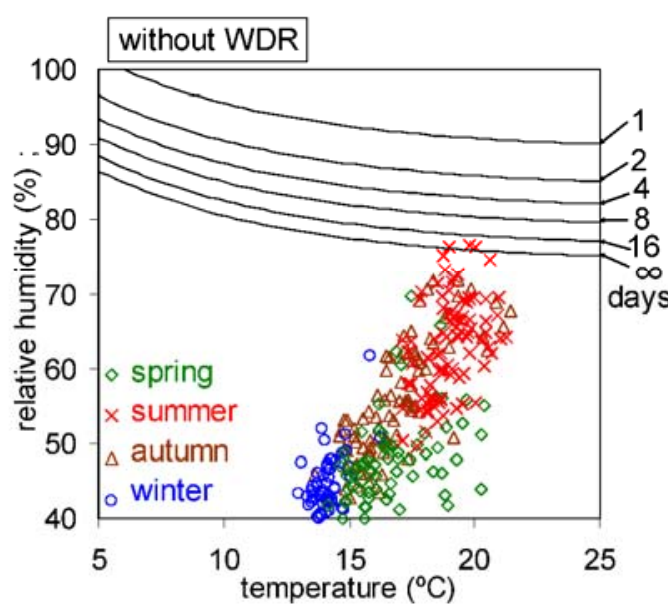

(c)

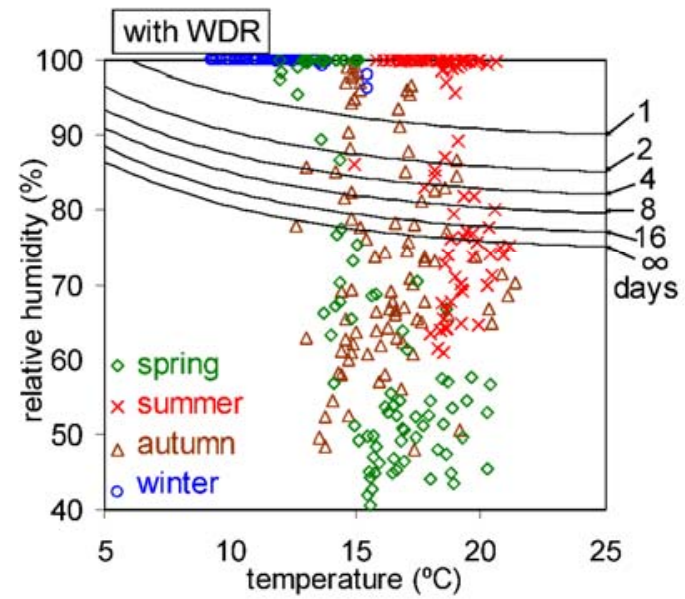

(b)

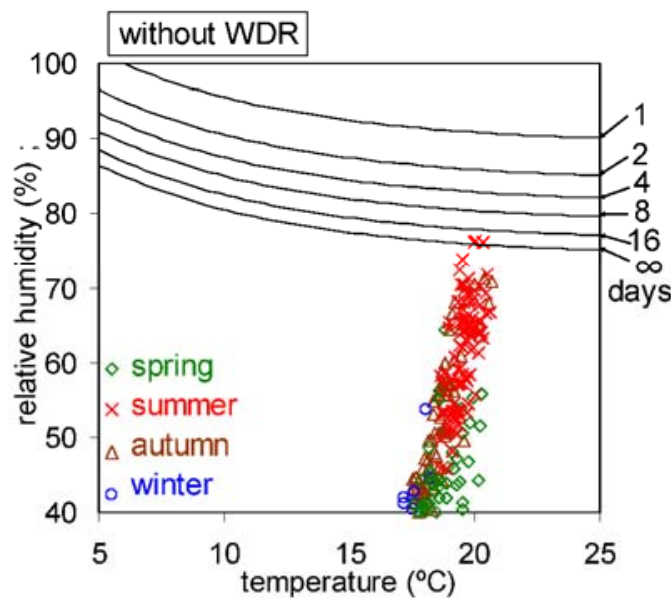

(d)

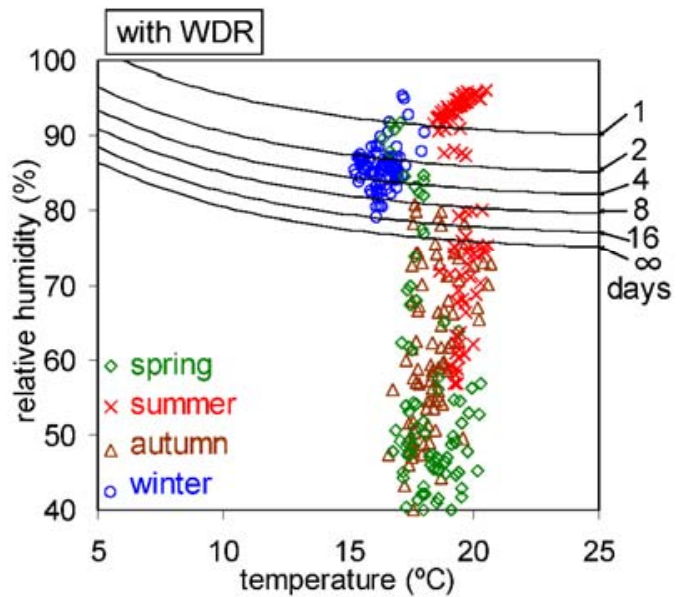

Fig. 8. Daily averaged temperature and humidity at the inside wall surfaces on the graph of generalised isopleths of the spore germination time (black solid lines) of the fungus mould for the substrate category I. (a) and (c) At the south-west facing edge of the wall; (b) and (d) at the south facing centre of the wall. In (a) and (b), no wind-driven rain load (WDR) is applied; in (c) and (d) wind-driven rain loads are applied. 
(a)

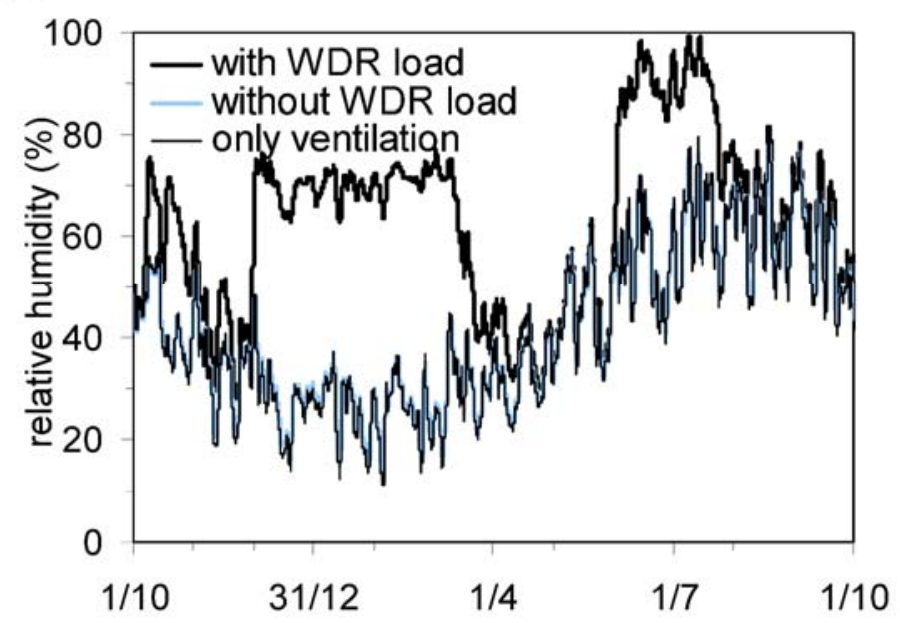

(b)

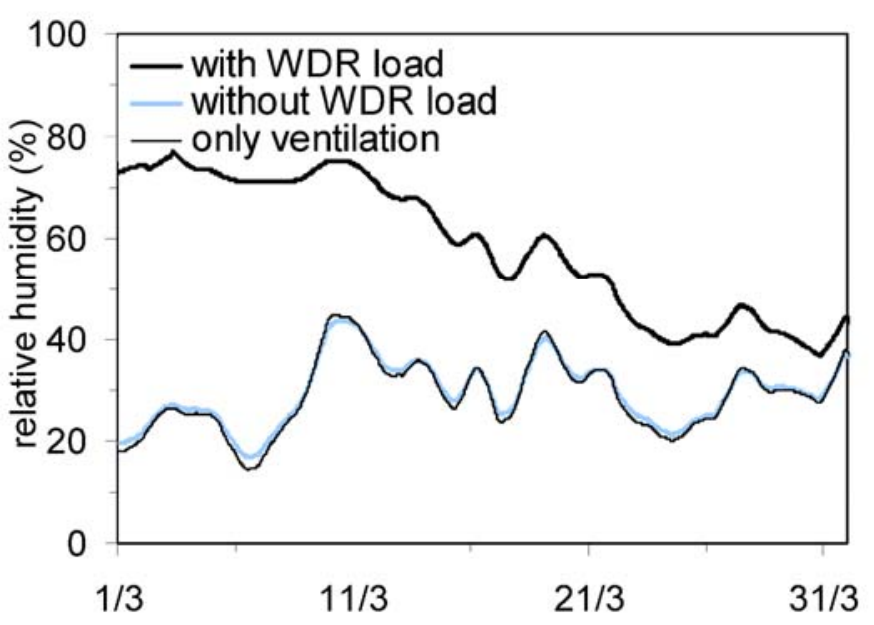

Fig. 9. (a) Time evolution of indoor relative humidity of the 3 cases over the year and (b) an excerpt of March. In one case (only ventilation), indoor relative humidity was calculated taking into account only constant ventilation rate and indoor temperature; in another case (without WDR), the heat and moisture transfer was taken into account in addition of the conditions of the first case; and in the last case (with WDR), WDR was taken into account in addition to the conditions of the second case. 